\title{
Establishment of a series of alien monosomic addition lines of Japanese bunching onion (Allium fistulosum L.) with extra chromosomes from shallot (A. cepa L. Aggregatum group) ${ }^{\dagger}$
}

\author{
Masayoshi Shigyo*, Yosuke Tashiro, Shiro Isshiki \\ and Sadami Miyazaki \\ Department of Biotechnology and Plant Breeding, Faculty of Agriculture, \\ Saga University, Saga 840, Japan
}

(Received 6 September 1996, accepted 19 December 1996)

\begin{abstract}
Forty one plants of alien monosomic addition lines of Allium fistulosum L. with extra chromosomes from A. cepa L. Aggregatum group ( FF $+\mathrm{nA})$ were produced through the second backcross of amphidiploids between these two species to $A$. fistulosum. Identification of the extra chromosomes in the 16 plants by elaborate karyotype analyses indicate that a complete series (eight different types) of the alien monosomic addition lines was established in Allium for the first time in this study. Chromosomal locations of malate dehydrogenase (MDH) gene, triosephosphate isomerase (TPI) gene and 5S rDNA of A. cepa Aggregatum group were determined using the series; The gene locus $M d h-1$ was located on $4 \mathrm{~A}, T p i-1$ on $3 \mathrm{~A}$ and a $5 \mathrm{~S}$ rDNA locus on 7A. Our previous and present studies using the alien monosomic addition lines revealed 11 genetic markers (isozyme and $5 \mathrm{~S}$ rDNA) assigned to all eight chromosomes of A. cepa Aggregatum group, and these markers reconfirmed the completion of the series. Extra chromosomes of 25 other plants were examined by means of simple analyses of the chromosome markers and karyotypes. Of the total 41 plants, frequencies of the alien monosomic addition lines with extra chromosomes $1 \mathrm{~A}$ to $8 \mathrm{~A}$ were as follows: $1 \mathrm{~A}, 5$ plants; $2 \mathrm{~A}, 3 ; 3 \mathrm{~A}, 5 ; 4 \mathrm{~A}, 9 ; 5 \mathrm{~A}, 4 ; 6 \mathrm{~A}, 2$; $7 \mathrm{~A}, 11$; and $8 \mathrm{~A}, 2$.
\end{abstract}

\section{INTRODUCTION}

Allium cepa L. consists of three groups, namely, Common onion group, Aggregatum group, and Proliferum group (Jones and Mann, 1963; Hanelt, 1990). The Common onion group and Aggregatum group include common onion and shallot, respectively (Jones and Mann, 1963; Hanelt, 1990). In both groups, large numbers of cultivars and strains have been developed and cultivated in many parts of the world (Jones and Mann, 1963).

In edible Alliums, shallot has the highest adaptability to tropical and sub-tropical zones and is an important crop in these zones (Astley et al., 1982). Shallot is usually propagated vegetatively, though it can flower and set seeds. Its easy husbandry and short growing period are favorable characteristics for the cultivation in the zones. Since population explosion is one of the most crucial topics today for the developing countries in the zones, many-sided stud-

\footnotetext{
* Corresponding author.

A part of this study was presented at the 1995 Autumn Meeting of the Japanese Society for Horticultural Science, Miyazaki, Japan
}

ies on this plant are demanded.

Shallot is similar to the common onion in morphological characters of inflorescence, but certainly differs in plant size, tillering and bulb formation (Atkin, 1953; Tashiro et al., 1982). Previous studies on the cytogenetics (Atkin, 1953; Tashiro et al., 1982) demonstrated that shallot could cross freely with common onion. Shallot is, therefore, the most important genetic resource for improvement of the common onion. The elucidation of the genetic systems of agronomic traits and the construction of genetic markers in shallot are imperative not only for the improvement of this plant but also for the efficient raising of common onion cultivars suitable for low latitude regions.

Interspecific $\mathrm{F}_{1}$ hybrids between $A$. cepa both common onion and shallot and $A$. fistulosum L. had been readily produced by several researchers and examined on their fertility (Emsweller and Jones, 1935a, b; Levan, 1936; Maeda, 1937; Cochran, 1942; Van der Meer and Van Benekom, 1978; Dolezel et al., 1980; Tashiro, 1984). Though most of the hybrids showed severe sterility, chromosome doubling had successfully restored the fertility of the hybrids. Triploid backcross progenies of them were 
developed under crossing with both parents (Levan, 1941; Tashiro, 1984). Tashiro et al., (1983) found the alien monosomic addition lines (AMALs) in the second backcross progenies.

The AMALs are efficacious for determining the chromosomal locations of genes and genetic markers. In Allium species, no complete series of the AMALs has been established, though a few efforts were made to produce AMALs between $A$. fistulosum and A. cepa both common onion and shallot (Tashiro et al., 1983; Peffley et al., 1985; De Vries et al., 1991).

Using some AMALs of $A$. fistulosum with the extra chromosomes from shallot, Shigyo et al. (1994, 1995a, 1995b) determined the chromosomal locations of eight isozyme genes in shallot; the gene locus Lap-1 on chromosome 1A, Got-1 and 6-Pgdh-2 on 2A, Idh-1 and Pgi-1 on 5A, Adh-1 and Got-2 on 6A, and Gdh-1 on 8A. These isozyme genes are useful as the chromosome markers in shallot. Further studies are necessary to establish chromosome markers on the remaining three chromosomes (3A, 4A, 7A).

The aims of the present study were to complete a series of AMALs of A. fistulosum with extra chromosomes from shallot and to establish the chromosome markers available for identification of all the chromosomes in shallot.

\section{MATERIALS AND METHODS}

Production of AMALs. A method to obtain the AMALs is presented in Fig. 1. The AMALs were selected from the second backcross progenies $\left(\mathrm{BC}_{2}\right)$ of amphidiploids between $A$. fistulosum and shallot. Following characters were investigated: 1 ) seed set in second backcross; 2) chromosome numbers of somatic cells in $\mathrm{BC}_{2}$; and 3) chromosome configurations at metaphase-I in pollen mother cells (PMCs) of $\mathrm{BC}_{2}$. The seed set is evaluated by the percentages of ovules that developed into seeds and germination rate (Tashiro, 1984). Somatic chromosomes of root tips were observed by Feulgen nuclear staining followed by squash method. Acetocarmine smears of PMCs were used for meiotic studies.

Identification of extra chromosomes. A haploid plant of shallot (Fig. 2) and diploid hybrids between shallot and A. fistulosum (Fig. 3) were used to measure arm lengths of the chromosomes. Mitotic cells of the diploid hybrids had two distinctive sub-telocentric chromosomes (6A from shallot and $6 \mathrm{~F}$ from $A$. fistulosum). In the present study, the chromosomes $6 \mathrm{~A}$ and $6 \mathrm{~F}$ were used as mediators to allow the comparison of chromosomes in different cells of several plants. The data obtained from each chromosome were converted to two standardized values, namely, relative chromosome length of shallot to the long arm length of $6 \mathrm{~F}$ (chromosome length/long arm length of $6 \mathrm{~F} ; \mathrm{RCL} 6 \mathrm{~F}$ ) and centromeric index (short arm length $\times$

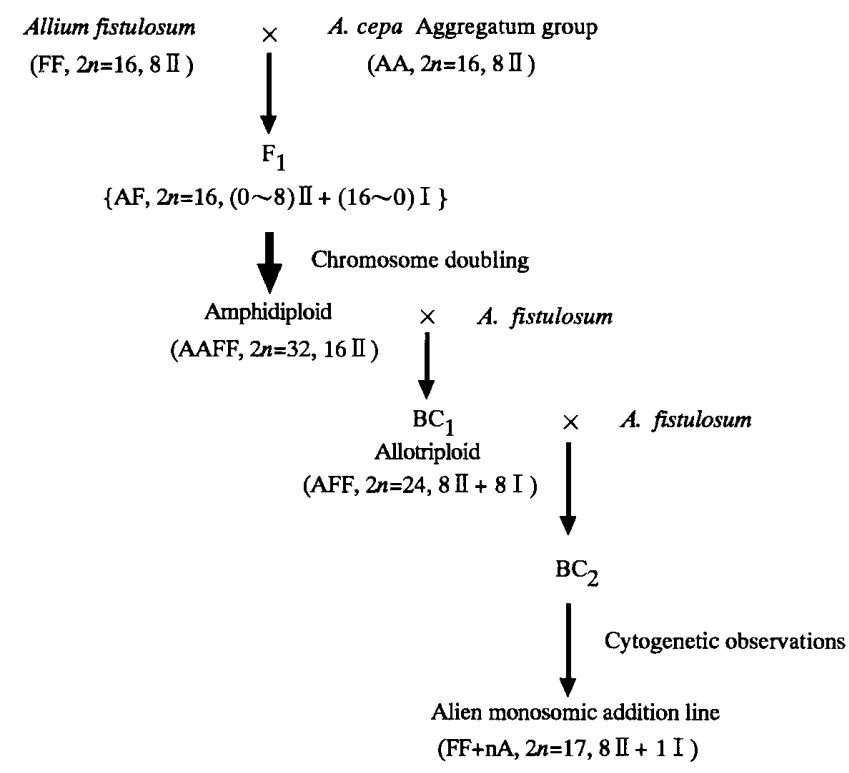

Fig. 1. Procedure for producing alien monosomic addition lines of $A$. fistulosum with extra chromosomes from shallot.

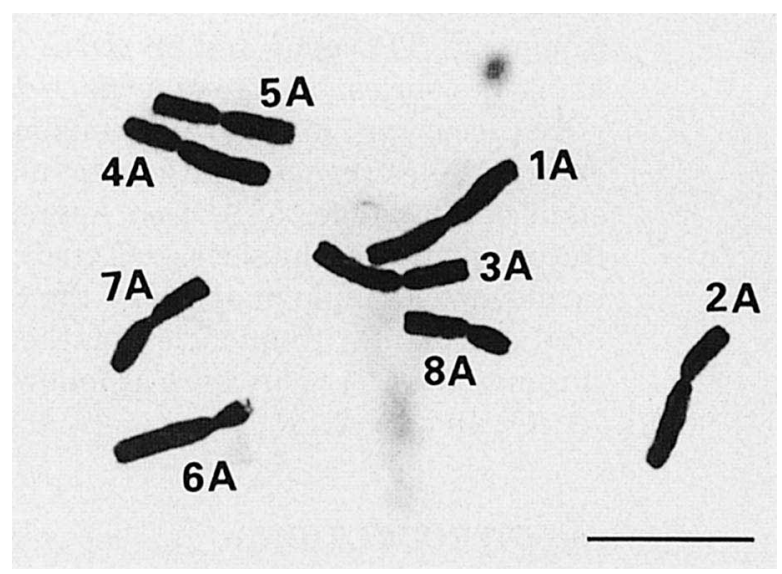

Fig. 2. Somatic metaphase chromosomes of a haploid plant of shallot. Scale bar $=10 \mu \mathrm{m}$.

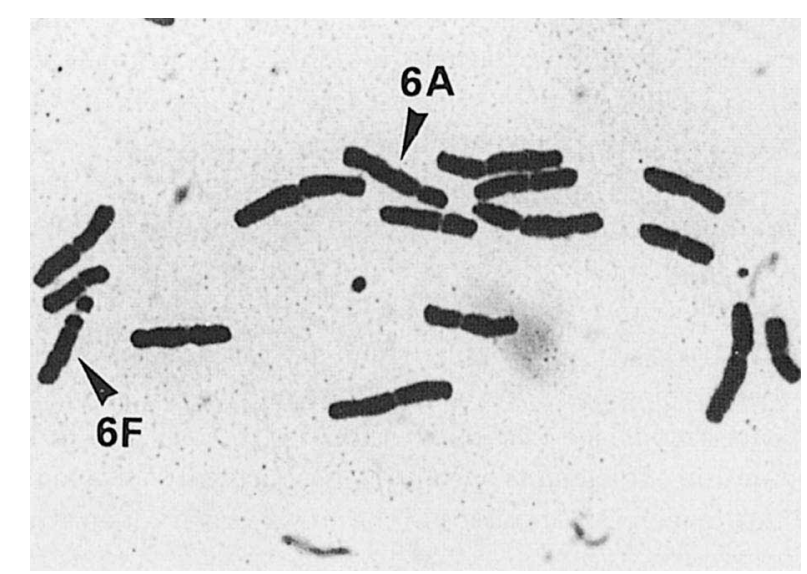

Fig. 3. Somatic metaphase chromosomes of a diploid hybrid between A. fistulosum and shallot. Arrowheads point to the subtelocentric chromosomes (6A, 6F). 
100/chromosome length; CI). The RCL6F was calculated through the following process; 1 ) the relative chromosome length of each chromosome to the long arm length of $6 \mathrm{~A}$ (RCL6A) was calculated using nine metaphase cells of the haploid plant; 2 ) a constant (a/b) was obtained by dividing the long arm length of $6 \mathrm{~A}$ (a) by that of $6 \mathrm{~F}(\mathrm{~b})$ in the diploid hybrid; 3) the RCL6A obtained from 1) was converted to RCL6F using the constant obtained from 2) (RCL6F = RCL6A $\times(\mathrm{a} / \mathrm{b}))$. The CI was obtained using haploid cells. The system of chromosome nomenclature for A. fistulosum and shallot was according to the general agreement of the Eucarpia 4th Allium Symposium (De Vries, 1990).

Sixteen out of the 41 plants of the AMALs obtained were used for elaborate karyotypic observations. The RCL6F and CI of the extra chromosome were calculated using at least three somatic cells in each plant of the AMAL.

Isozyme analyses. Preliminary isozyme analyses of several enzymes in addition to the seven enzymes previously reported had detected interspecific polymorphisms of malate dehydrogenase (MDH, EC 1.1.1.37) and triosephosphate isomerase (TPI, EC 5.3.1.1) isozymes between shallot and A. fistulosum. These two enzymes were therefore analyzed in this study. The enzymes were extracted from young expanding leaves according to the crude extraction method described by Wendel (1983). The gel and electrode buffer from the starch gel system D described by Wendel (1983) were adopted for $\mathrm{MDH}$ and those from the starch gel system 8 by Soltis et al. (1983) for TPI. The staining procedures for $\mathrm{MDH}$ and TPI were conducted according to Wendel (1983) and Soltis et al. (1983), respectively.
Analysis of 5S rDNA. In preliminary analyses of 5S and 18S rDNA in shallot and A. fistulosum, an interspecific polymorphism had been observed between their electrophoretic profiles of PCR products for the 5S rDNA. In this study, only the 5S rDNA analysis was performed to determine the chromosomal location. Total DNA was isolated from the leaves or florets by the micro extraction method (Dubouzet et al., 1996). A full length of 5S rDNA was amplified by PCR using the 5S rDNA primer set (5'CGGTGCATTAATGCTGGTAT-3', 5'-CCATCAGAACTCCGCAGTTA-3') according to Hizume (1993, 1994). The amplified DNA fragments were electrophoretically separated by $1.5 \%$ agarose gel containing ethidium bromide in TAE buffer and the gels were photographed under UV light.

\section{RESULTS AND DISCUSSION}

Production of AMALs. After crossing with A. fistulosum, the allotriploid showed a very low seed set, and the germination rate of the seeds obtained was also low (Table 1). However, the survival rate of the germinated seeds was not low, and $274 \mathrm{BC}_{2}$ plants were ultimately obtained. The chromosome count using 253 of the 274 $\mathrm{BC}_{2}$ plants revealed that the chromosome numbers in most of the plants varied from 16 to 24 , and 47 plants with 17 chromosomes were obtained (Table 2, Fig. 4). Forty six out of the 47 plants were used for the meiotic observations. At metaphase-I, all PMCs of 43 plants formed eight bivalents and one univalent $(8 \mathrm{II}+1 \mathrm{I})($ Fig. 5$)$. In the remaining three plants, the PMCs formed 8II + 1I and $7 \mathrm{II}+3 \mathrm{I}$. The bivalents formed localized chiasmata those are a characteristic of the meiotic chromosomes of

Table 1. Seed set, seed germination, and seedling survival in the backcrossing of allotriploid to A. fistulosum

\begin{tabular}{ccccccc}
\hline \hline $\begin{array}{c}\text { Number } \\
\text { of } \\
\text { flowers } \\
\text { pollinated }\end{array}$ & $\begin{array}{c}\text { Number } \\
\text { of } \\
\text { seeds } \\
\text { produced }\end{array}$ & $\begin{array}{c}\text { Percentage } \\
\text { of } \\
\text { ovules that } \\
\text { developed } \\
\text { into seeds }\end{array}$ & $\begin{array}{c}\text { Number } \\
\text { of } \\
\text { seeds that } \\
\text { germinated }\end{array}$ & $\begin{array}{c}\text { Percentage } \\
\text { of seeds } \\
\text { that } \\
\text { germinated }\end{array}$ & $\begin{array}{c}\text { Number of } \\
\text { seedlings } \\
\text { that } \\
\text { survived }\end{array}$ & $\begin{array}{c}\text { Percentage } \\
\text { of } \\
\text { seedlings } \\
\text { that } \\
\text { survived }\end{array}$ \\
\hline 6870 & 2.7 & 404 & 36.0 & 274 \\
\hline${ }^{\text {a }}$ Percentage of ovules that developed into seeds \\
Number of seeds produced
\end{tabular}

Table 2. Variation of chromsome numbers in $\mathrm{BC}_{2}$ progenies

\begin{tabular}{cccccccccccc}
\hline \hline \multirow{2}{*}{$\begin{array}{c}\text { Number } \\
\text { of } \\
\text { plants }\end{array}$} & \multicolumn{10}{c}{ Frequency of plants } \\
\cline { 2 - 11 } observed & 16 & 17 & 18 & 19 & 20 & 21 & 22 & 23 & 24 & $25<$ \\
\hline 253 & 14 & 47 & 45 & 30 & 26 & 41 & 33 & 14 & 1 & 2 \\
\hline
\end{tabular}




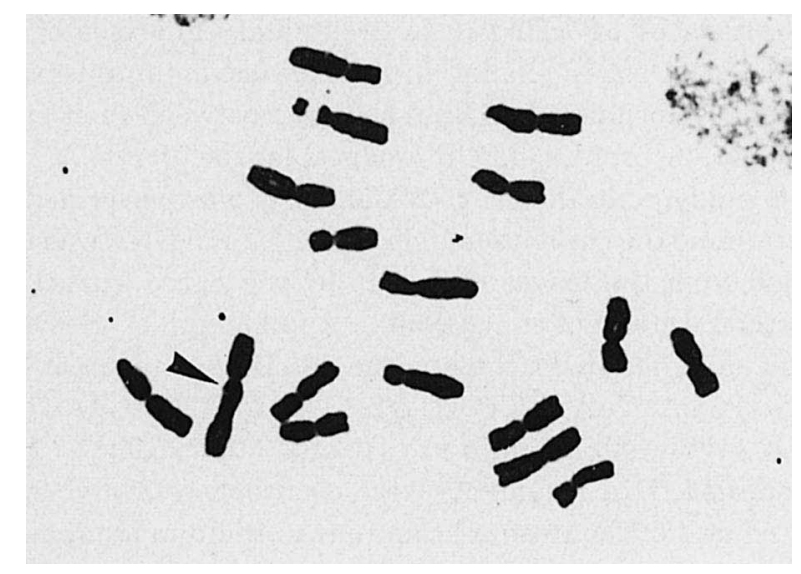

Fig. 4. Somatic metaphase chromosomes of a $\mathrm{BC}_{2}$ plant with 17 chromosomes. Arrowhead points to the extra chromosome 2A.

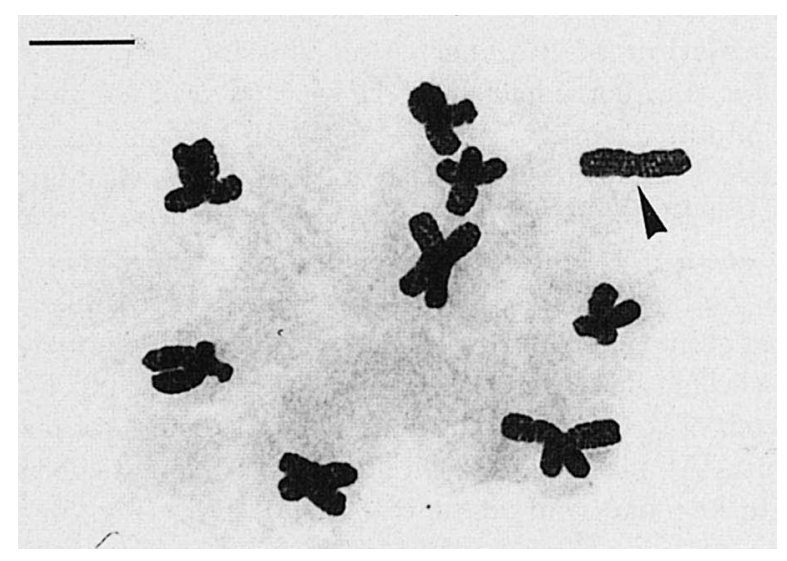

Fig. 5. Chromosome pairing at meiotic metaphase-I in a PMC of a $\mathrm{BC}_{2}$ plant with 17 chromosomes. Arrowhead points to the univalent chromosome $1 \mathrm{~A}$. Scale bar $=10 \mu \mathrm{m}$.

A. fistulosum. Since one plant showed an abnormal karyotype and one other plant was dead, 41 plants were selected as normal AMALs.

Identification of extra chromosomes. The constant $\mathrm{a} / \mathrm{b}$ was 1.25. Numerical data (RCL6F, CI) for the chromosomes of the haploid plant of shallot are summarized in Table 3. The RCL6F varied from 1.34 to 2.24 and the CI from 23.07 to 48.40, and all chromosomes of shallot could be identified with the combination of RCL6F and CI. RCL6F was used for the first time to compare chromosomes in different cells of Allium plants. The CIs obtained from shallot in this study were quite similar to those from common onion in the previous studies (Kalkman, 1984; Peffley and Currah, 1988).

The numerical data of the extra chromosomes are shown in Table 4. The RCL6F of the extra chromosomes varied from 1.34 to 2.33 and the CI from 24.31 to 48.11 . The two data from Table 4 were plotted on a two-dimensional dia-
Table 3. Numerical data of chromosomes of A. серa Aggregatum group

\begin{tabular}{|c|c|c|}
\hline Chromosome & $\mathrm{RCL} 6 \mathrm{~F}^{\mathrm{a}}$ & $\mathrm{CI}^{\mathrm{b}}$ \\
\hline $1 \mathrm{~A}$ & $2.24 \pm 0.04^{\mathrm{c}}$ & $48.25 \pm 0.44^{\mathrm{c}}$ \\
\hline $2 \mathrm{~A}$ & $2.03 \pm 0.05$ & $37.04 \pm 0.76$ \\
\hline $3 \mathrm{~A}$ & $1.92 \pm 0.03$ & $42.30 \pm 0.59$ \\
\hline $4 \mathrm{~A}$ & $1.86 \pm 0.03$ & $40.19 \pm 0.62$ \\
\hline $5 \mathrm{~A}$ & $1.81 \pm 0.05$ & $46.39 \pm 0.98$ \\
\hline $6 \mathrm{~A}$ & $1.62 \pm 0.01$ & $23.07 \pm 0.28$ \\
\hline $7 \mathrm{~A}$ & $1.54 \pm 0.05$ & $48.40 \pm 0.42$ \\
\hline $8 \mathrm{~A}$ & $1.34 \pm 0.03$ & $39.03 \pm 0.75$ \\
\hline \multicolumn{3}{|l|}{${ }^{a} \mathrm{RCL} 6 \mathrm{~F}=$} \\
\hline \multicolumn{3}{|c|}{ long arm length of chromosome $6 \mathrm{~F}$ of $A$. fistulosum } \\
\hline${ }^{\mathrm{b}} \mathrm{CI}=$ short $\mathrm{a}$ & $\times 100$ & \\
\hline
\end{tabular}

For explanation of abbreviations see text.

${ }^{\mathrm{c}}$ Data are shown with mean $\pm \mathrm{SE}$.

Means derived from 9 cells.

gram with the standardized values for the eight chromosomes of shallot from Table 3 (Fig. 6). The 16 points obtained from the extra chromosomes of 16 AMALs on the diagram were successfully plotted close to the eight points of the standardized values for the chromosomes of shallot. 1A was detected in AMALs 119 and 130, 2A in 132 and $199,3 \mathrm{~A}$ in 5 and $42,4 \mathrm{~A}$ in 32 and $158,5 \mathrm{~A}$ in 24 and $71,6 \mathrm{~A}$ in 120 and 308, 7A in 23 and 246 , and $8 \mathrm{~A}$ in 65 and 240. From the results mentioned above, it is concluded that a complete series (eight different types) of the AMALs, has been established in the present study (Fig. 7).

\section{Chromosomal locations of the isozyme genes and 5S rDNA. \\ 1) $\mathrm{MDH}$}

Five bands were detected both in A. fistulosum and shallot (Fig. 8). Although the positions of four (bands 3, 4, 5, 6 ) out of the five bands were identical between these two species, the remaining bands, band 1 in A. fistulosum and band 2 in shallot, showed different migration distances. Ulloa-G et al. (1995) reported that the genes manifesting the two bands had an allelism in A. fistulosum and common onion, and identified the gene locus Mdh-1. Bands 1 and 2 in the present study seem to be manifested by alleles at Mdh-1. Therefore, genetic analysis of MDH bands was concentrated on this locus. At Mdh-1, the amphidiploid and allotriploid possessed both bands 1 and 2 (Fig. 9). In both plants of the AMALs FF + 4A (32 and 158), the band patterns were identical with those of the amphidiploid and allotriploid. Other AMALs had the same band pattern as A. fistulosum. These results reveal that $M d h-1$ is on $4 \mathrm{~A}$. 2) $T P I$

Three bands were observed in A. fistulosum, and two bands in shallot (Fig. 10). The band patterns clearly 
Series of alien monosomic addition lines in Allium

Table 4. Numerical data of extra chromosomes in alien monosomic addition lines

\begin{tabular}{rcccc}
\hline \hline Plant No. & $\begin{array}{l}\text { No. of cells } \\
\text { examined }\end{array}$ & RCL6F & CI & $\begin{array}{c}\text { Identified } \\
\text { extra chromosomes }\end{array}$ \\
\hline 5 & 5 & $1.99 \pm 0.05^{\mathrm{a}}$ & $41.16 \pm 0.59^{\mathrm{a}}$ & $3 \mathrm{~A}$ \\
23 & 3 & $1.60 \pm 0.03$ & $47.98 \pm 0.78$ & $7 \mathrm{~A}$ \\
24 & 5 & $1.83 \pm 0.01$ & $47.09 \pm 0.59$ & $5 \mathrm{~A}$ \\
32 & 7 & $1.90 \pm 0.04$ & $40.47 \pm 0.60$ & $4 \mathrm{~A}$ \\
42 & 6 & $1.95 \pm 0.03$ & $42.48 \pm 0.30$ & $3 \mathrm{~A}$ \\
65 & 3 & $1.35 \pm 0.03$ & $39.78 \pm 1.24$ & $8 \mathrm{~A}$ \\
71 & 3 & $1.85 \pm 0.05$ & $46.11 \pm 0.20$ & $5 \mathrm{~A}$ \\
119 & 4 & $2.30 \pm 0.06$ & $47.73 \pm 0.28$ & $1 \mathrm{~A}$ \\
120 & 4 & $1.64 \pm 0.07$ & $24.31 \pm 1.10$ & $6 \mathrm{~A}$ \\
130 & 3 & $2.33 \pm 0.11$ & $48.11 \pm 0.67$ & $2 \mathrm{~A}$ \\
132 & 4 & $2.15 \pm 0.13$ & $35.62 \pm 1.16$ & $4 \mathrm{~A}$ \\
158 & 3 & $1.86 \pm 0.01$ & $39.51 \pm 1.24$ & $2 \mathrm{~A}$ \\
199 & 4 & $2.10 \pm 0.06$ & $35.24 \pm 1.44$ & $8 \mathrm{~A}$ \\
240 & 3 & $1.34 \pm 0.09$ & $40.72 \pm 1.15$ & $7 \mathrm{~A}$ \\
246 & 4 & $1.61 \pm 0.07$ & $47.57 \pm 0.63$ & $6 \mathrm{~A}$ \\
308 & 3 & $1.59 \pm 0.03$ & $24.31 \pm 1.02$ & \\
\hline
\end{tabular}

${ }^{a}$ Data are shown with mean $\pm \mathrm{SE}$.

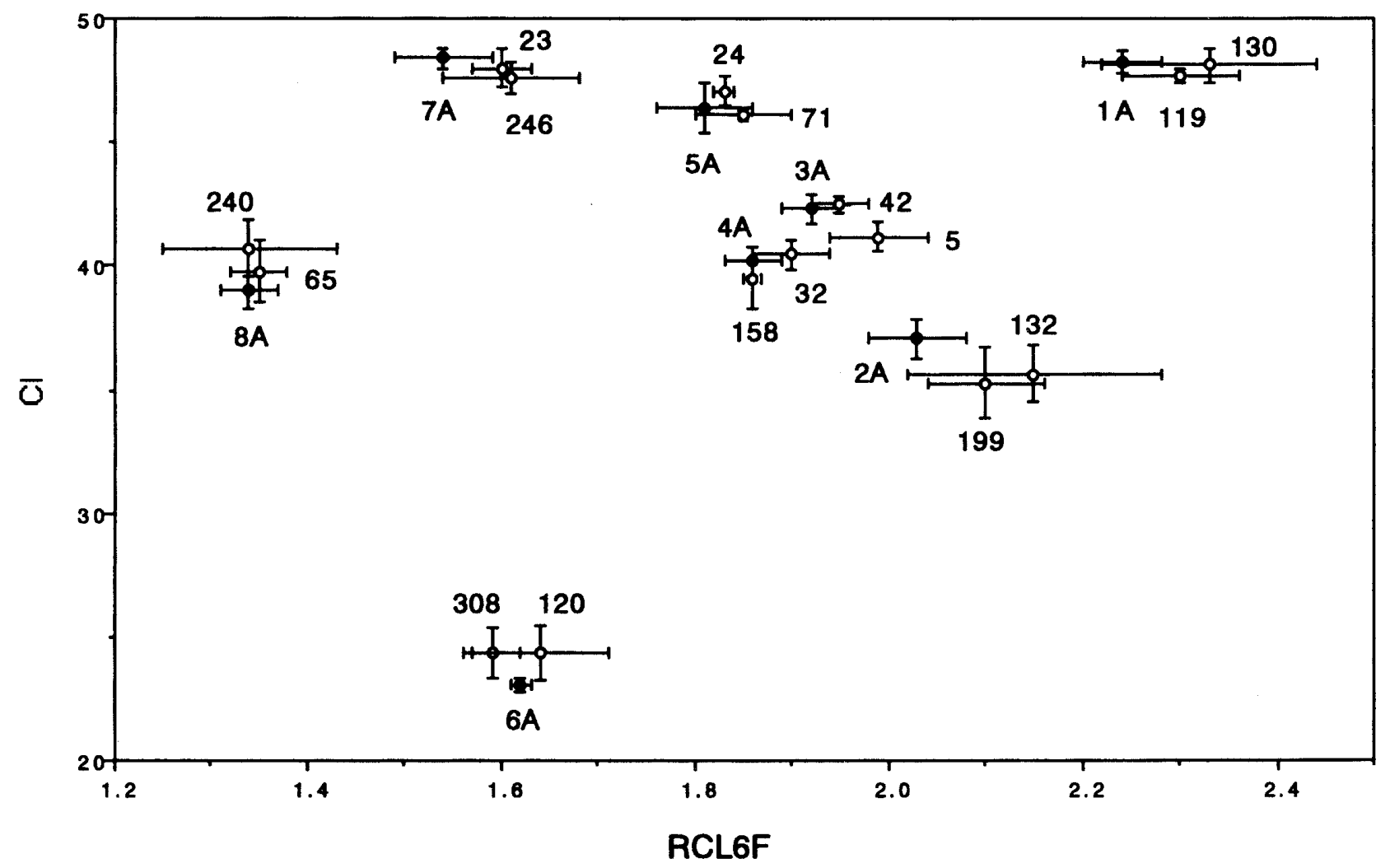

Fig. 6. Two-dimensional presentation of chromosomes in shallot and the extra chromosomes in alien monosomic addition lines. chromosomes of shallot. $\bigcirc$, chromosomes of alien monosomic addition lines (Numbers indicate line Nos.). $\mapsto$, SE (Standard error).

showed an interspecific polymorphism between these two species. Band 1 was species specific in A. fistulosum, and band 2 in shallot. Bands 3 and 4 were common to the two species. The amphidiploid and allotriploid possessed all four bands observed in the parents. The two plants of the
AMALs FF + 3A (5 and 42) showed a band pattern similar to that of the amphidiploid and allotriploid. The AMALs $\mathrm{FF}+1 \mathrm{~A}(130), \mathrm{FF}+2 \mathrm{~A}$ (132 and 199), FF + 4A (32), FF + $5 \mathrm{~A}$ (24 and 71), FF + 6A (308), FF + 7A (23 and 246), and $\mathrm{FF}+8 \mathrm{~A}(65)$ had a band pattern identical with $A$. 


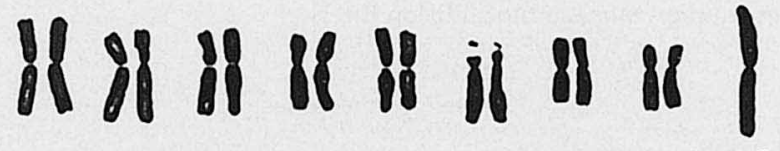 $1 \mathrm{~A}$ \\ HIHAH H if $\|$ i

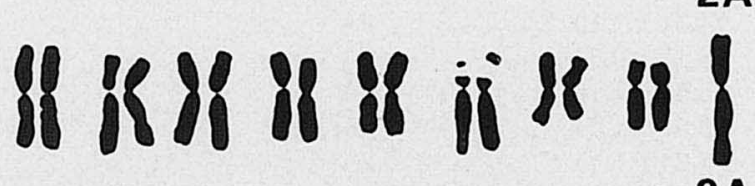 \\ $3 \mathrm{~A}$

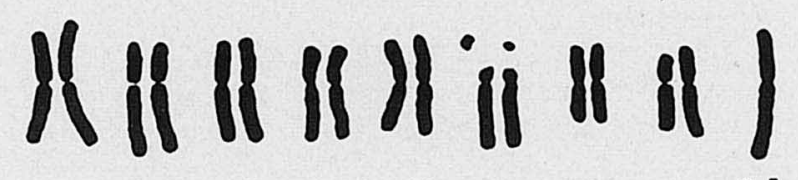

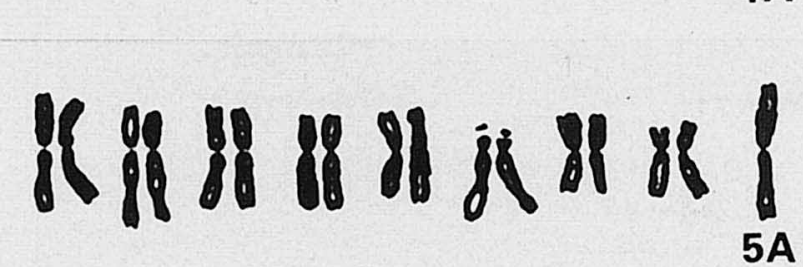 \\ \|\|\|\|$\|j\| \|$ " \\ 6A \\ \|\|\|\|\|\|\|\|$\|$

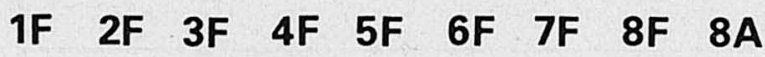

Fig. 7. Somatic metaphase chromosomes of a series of alien monosomic addition lines $(\mathrm{FF}+1 \mathrm{~A}, 130 ; \mathrm{FF}+2 \mathrm{~A}, 132 ; \mathrm{FF}+3 \mathrm{~A}, 5$; $\mathrm{FF}+4 \mathrm{~A}, 32 ; \mathrm{FF}+5 \mathrm{~A}, 71 ; \mathrm{FF}+6 \mathrm{~A}, 120 ; \mathrm{FF}+7 \mathrm{~A}, 23 ; \mathrm{FF}+8 \mathrm{~A}, 65)$ $1 \mathrm{~F}-8 \mathrm{~F}$ : Chromosomes from $A$. fistulosum. $1 \mathrm{~A}-8 \mathrm{~A}$, extra chromosomes from shallot.

fistulosum. The AMALs FF + 1A (119), FF + 4A (158), FF + 6A (120), and FF + 8A (240) had a band pattern similar to that of $A$. fistulosum except that band 1 was absent. It seems that the absent is caused by the heterozygosity of the genes controlling the band 1 in A. fistulosum. These

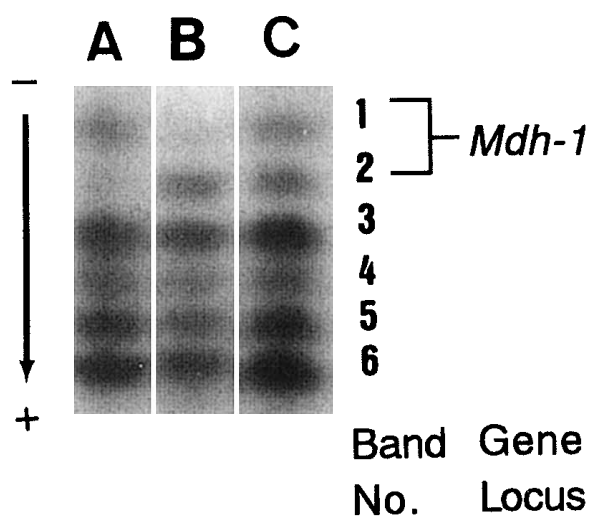

Fig. 8. MDH zymograms of A. fistulosum A; shallot B; and amphidiploid C.

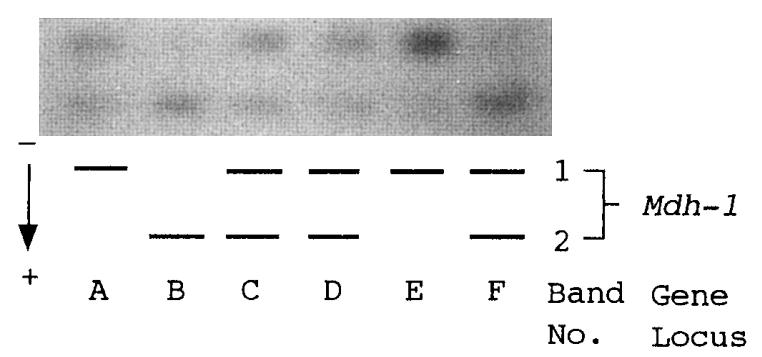

Fig. 9. $\mathrm{MDH}$ zymograms of A. fistulosum A; shallot B; amphidiploid C; allotriploid D; AMAL FF + 2A (132) E; and AMAL FF + $4 \mathrm{~A}$ (32) F. A schematic illustration is shown in the bottom half of the figure. The zymogram of AMAL FF + 4A (158) showed the pattern same as F. Other 13 AMALs showed A. Zymograms of them are not shown.

results indicate that the gene locus controlling band 2 , designated tentatively as Tpi-1, is on 3A.

3) $5 \mathrm{~S}$ rDNA

The electrophoretic profile of PCR products for $5 \mathrm{~S}$ rDNA in A. fistulosum showed three bands; 5S-Rdna-1 (approximating $1000 \mathrm{bp}$ ), 5S-Rdna-2 (700 bp), and 5S-Rdna-4 (350 bp) (lane A in Fig. 11). In shallot, one other band, 5SRdna-3 (approximating $500 \mathrm{bp}$ ), was detected in addition to the three bands observed in A. fistulosum (lane B). The amphidiploid and allotriploid had all the four bands observed in the parents (lanes C and D). In both plants of the AMALs FF + 7A (23 and 246), all the four bands were observed (lane K). Other AMALs had the three bands 5 SRdna-1, 5S-Rdna-2 and 5S-Rdna-4 but did not have 5SRdna-3 (lanes E, F, G, H, I, J, L). These results reveal that $5 \mathrm{~S}-\mathrm{Rdna}-3$ is on 7A. By means of in situ hybridization, Hizume (1994) reported that the common onion had two 5S rDNA loci at the interstitial regions of the short arm of a small metacentric chromosome, chromosome 7C. As described in the introduction, the shallot is a plant closely related to the common onion. It seems that the chromosome 7A and 7C are homoeologous to each other. 


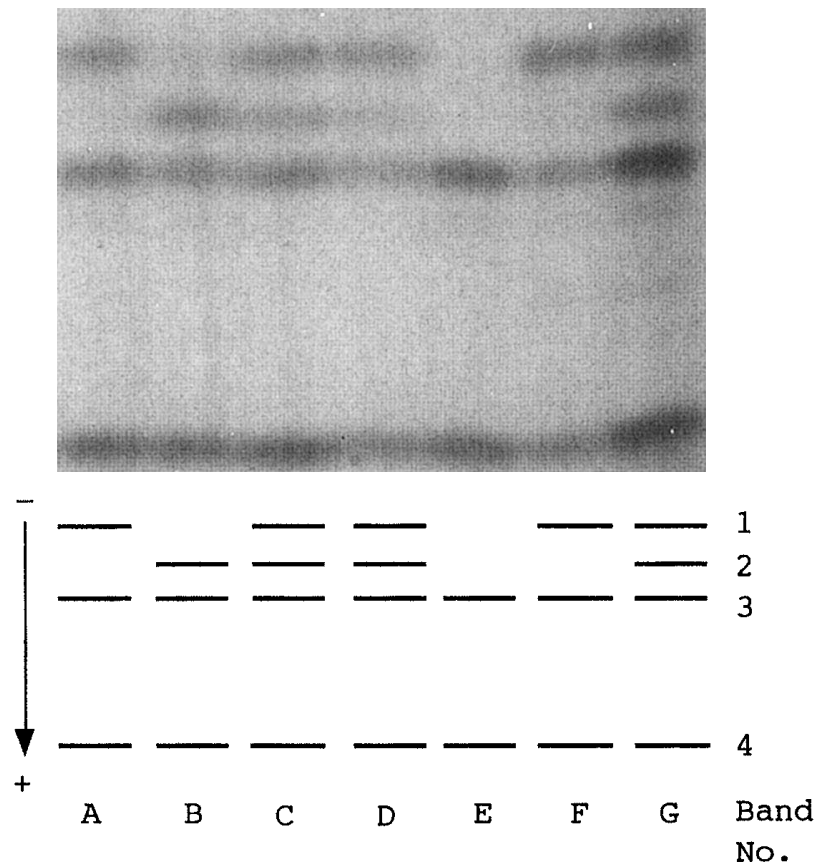

Fig. 10. TPI zymograms of A. fistulosum A; shallot B; amphidiploid C; allotriploid D; AMAL FF + 1A (130) E; AMAL FF + 8A (65) $\mathrm{F}$; and AMAL FF + 3A (5) G. A schematic illustration is shown in the bottom half of the figure. The zymogram of AMAL $\mathrm{FF}+3 \mathrm{~A}(42)$ showed the pattern same as G. Other 12 AMALs showed E or F. Zymograms of them are not shown.
Table 5. Chromosome markers on chromosomes of A. cepa Aggregatum group established in previous and present studies

\begin{tabular}{|c|c|}
\hline Chromosome & Chromosome marker \\
\hline $1 \mathrm{~A}$ & $\operatorname{Lap}-1^{\mathrm{b}}$ \\
\hline $2 \mathrm{~A}$ & Got $-1^{\mathrm{b}}, 6-P g d h-2^{\mathrm{b}}$ \\
\hline $3 \mathrm{~A}$ & Tpi-1 \\
\hline $4 \mathrm{~A}$ & $M d h-1$ \\
\hline $5 \mathrm{~A}$ & $I d h-1^{\mathrm{c}}, P g i-1^{\mathrm{c}}$ \\
\hline $6 \mathrm{~A}$ & Adh-1 ${ }^{\mathrm{b}}$, Got-2 ${ }^{\mathrm{a}}$ \\
\hline $7 \mathrm{~A}$ & 5S-Rdna-3 \\
\hline $8 \mathrm{~A}$ & $G d h-1^{\mathrm{b}}$ \\
\hline
\end{tabular}

a Data from Shigyo et al. (1994).

${ }^{\mathrm{b}}$ Data from Shigyo et al. (1995a).

${ }^{\mathrm{c}}$ Data from Shigyo et al. (1995b).

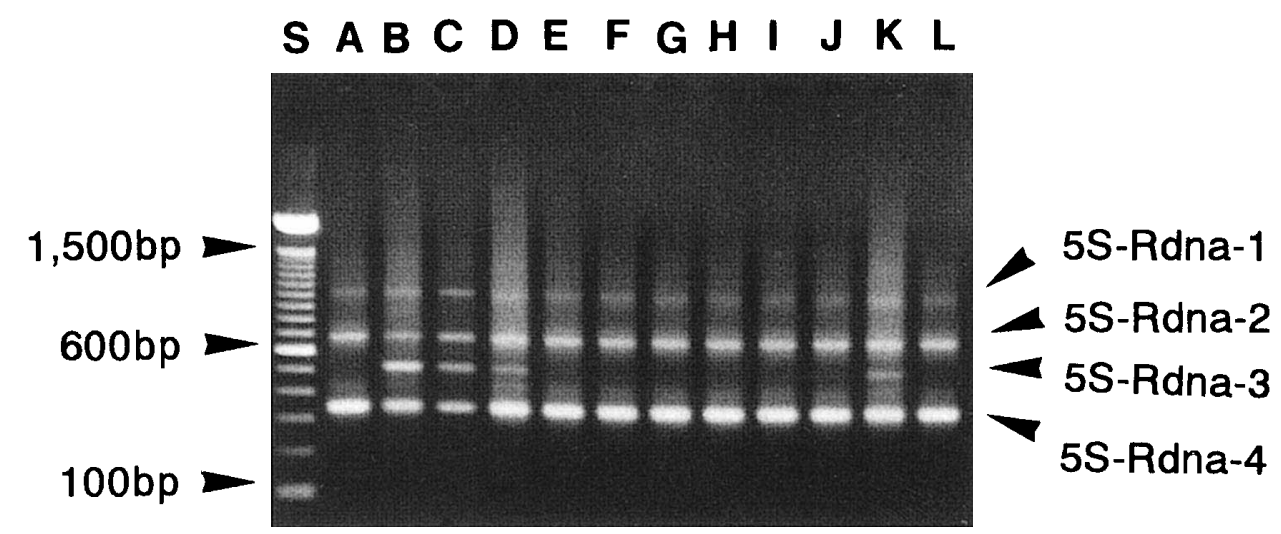

Fig. 11. Amplification profiles for 5S rDNA in A. fistulosum A; shallot B; amphidiploid C; allotriploid D; AMAL FF + 1A (130) E; AMAL FF + 2A (132) F; AMAL FF + 3A (5) G; AMAL FF + 4A (32) H; AMAL FF + 5A (71) I; AMAL FF + 6A (120) J; AMAL FF + 7A (23) K; and AMAL FF + 8A (65) L, S: Size marker (100-bp DNA ladder). The amplification profile of AMAL FF + 7A (246) showed the pattern same as K. Other seven AMALs showed A. Amplification profiles of them are not shown.

Therefore, the result in the present study using AMALs shows good agreement with that of Hizume.

From the present study it is concluded that the $M d h-1$ is located on the chromosome $4 \mathrm{~A}$, the $T p i-1$ on $3 \mathrm{~A}$, and a $5 \mathrm{~S}$ rDNA gene locus on 7A. Our previous studies using some AMALs allocated eight chromosome markers to the chromosome 1A, 2A, 5A, 6A, and 8A. Thus, we have completed assignment of at least one chromosome marker to each chromosome of shallot (Table 5). These chromosome markers also demonstrate that a series of AMALs has been established. Furthermore, extra chromosomes of 25 other plants of AMALs were examined by means of uncomplicated analyses of the chromosome markers and karyotypes. Frequencies of the AMALs with the extra chromosomes $1 \mathrm{~A}$ to $8 \mathrm{~A}$ in all 41 plants are summarized in Fig. 12. There was a tendency for the numbers of plants of the 


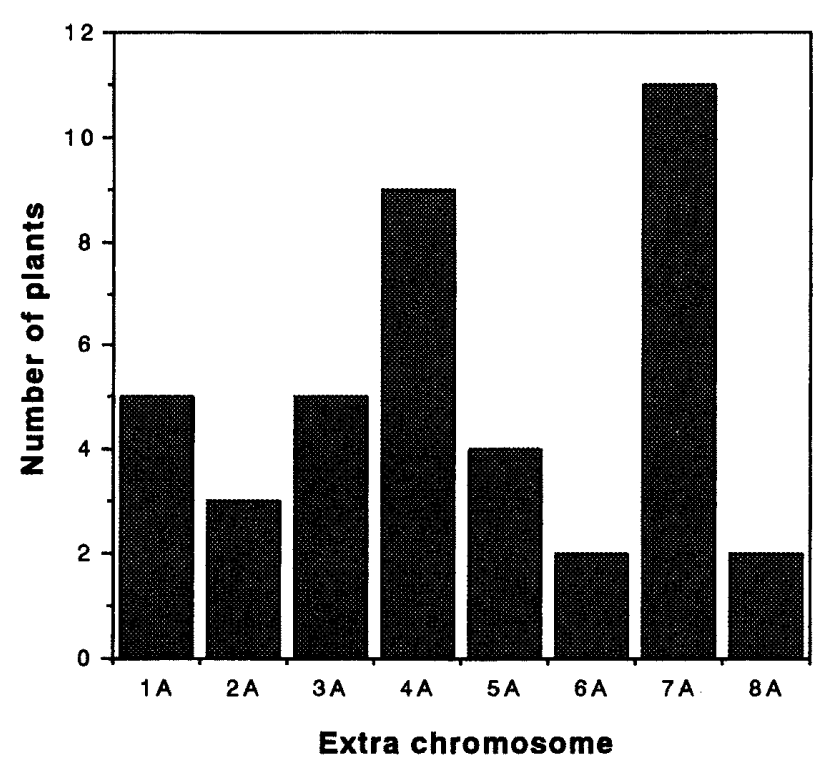

Fig. 12. Frequencies of alien monosomic addition lines with extra chromosomes $1 \mathrm{~A}$ to $8 \mathrm{~A}$.

AMALs with $4 \mathrm{~A}$ and $7 \mathrm{~A}$ to be larger than those with other chromosomes and for those with $6 \mathrm{~A}$ and $8 \mathrm{~A}$ to be less than others. There is a possibility that the extra chromosomes affect the survival rates of the AMALs.

The chromosome markers established in our studies will be useful to determine the chromosomal locations of the other genes and genetic markers linked with them. The RAPD and RFLP analyses of the series of AMALs completed in the present study may efficiently provide a large number of chromosome markers. Furthermore, if genetic distances of the chromosome markers are estimated, rapid construction of a genetic map will be possible in shallot. The genetic map will enhance future improvements of shallot and its allies.

The authors are grateful to Y. Takagi of Saga University for his valuable suggestions and continuing encouragement. The authors express their gratitude to L. Filippi of Saga University for reviewing the manuscript. The research was supported in part by Grants-in-Aid for Research Fellow of the Japan Society for the Promotion of Science (No.0058) from the Ministry of Education, Science, Sports, and Culture of Japan.

\section{REFERENCES}

Astley, D., Innes, N. L. and Van der Meer, Q. P. (1982) Genetic resources of Allium species - a global report. IBPGR Secretariat, Rome 1982, 7.

Atkin, J. D. (1953) Genetic and cytological studies of the Allium cepa $\times$ A. ascalonicum. Ph. D. Thesis, Univ. Calif. Davis, CA.

Cochran, F. D. (1942) Cytogenetic studies of the species hybrid $A$. fistulosum and A. ascalonicum and its backcross progenies. $\mathrm{Ph}$. D. Thesis, Univ. Calif. Davis, CA.

De Vries, J. N. (1990) Onion chromosome nomenclature and homoeology relationships-workshop report. Euphytica 49,
$1-3$.

De Vries, J. N., Zevenbergen, M. J., Huibers, W.H.C. and Jongerius, M.C. (1991) Monosomic additions of Allium cepa L. in a diploid $A$. fistulosum L. background. Proceedings of an international symposium at Gatersleben, Germany, June 1113, 1991. (eds.: P. Hanelt, K. Hammer, and H. Knupffer), pp. 331-333. Institute of genetics and crop plant research. Gatersleben, Germany.

Dolezel, J., Novák, F. J. and Luzny, J. (1980) Embryo development and in vitro culture of Allium cepa and its interspecific hybrids. Z. Pflanzenzucht. 85, 177-184.

Dubouzet, J., G., Etoh, T., Arisumi, K. and Yoshitake, T. (1996) A diagnostic tests to confirm interspecific Allium hybrids using random amplified polymorphic DNA from crude leaf DNA extracts. J. Jpn. Soc. Hortic. Sci. 65, 321-326.

Emsweller, S. L. and Jones, H. A. (1935a) An interspecific hybrid in Allium. Hilgardia 9, 265-273.

Emsweller, S. L. and Jones, H. A. (1935b) Meiosis in Allium fistulosum, Allium cepa and their hybrid. Hilgardia 9, 277288.

Hanelt, P. (1990) Taxonomy, evolution, and history. In: Onions and allied crops. Vol.1 (eds. H. D. Rabinowitch and J. L. Brewster), pp.1-26. CRC Press, Inc., Boca Raton, FL.

Hizume, M. (1993) Chromosomal localization of 5S rRNA genes in Vicia faba and Crepis capillaris. Cytologia 58, 417-421.

Hizume, M. (1994) Allodiploid nature of Allium wakegi Araki revealed by genomic in situ hybridization and localization of $5 \mathrm{~S}$ and 18S rDNAs. Jpn. J. Genet. 69, 407-415.

Jones, H. A. and Mann, L. K. (1963) I World production, II History, III Classification and identification (eds: H. A. Jones and L. K. Mann), pp. 1-46. Leonard Hill [Books] Ltd., London.

Kalkman, E. R. (1984) Analysis of the C-banded karyotype of Allium cepa L. standard system of nomenclature and polymorphism. Genetica 65, 141-148.

Levan, A. (1936) Die Zytologie von Allium cepa $\times$ A. fistulosum. Hereditas 21, 195-214.

Levan, A. (1941) The cytology of the species hybrid Allium cepa $\times$ A. fistulosum and its polyploid derivatives. Hereditas 27, 253-272.

Maeda, T. (1937) Chiasma studies in Allium fistulosum, Allium cepa and their $\mathrm{F}_{1}, \mathrm{~F}_{2}$, and backcross hybrids. Jpn. J. Genet. 13, 146-159.

Peffley, E.B. and Currah, L. (1988) The chromosomal locations of enzyme-coding genes in $A d h-1$ and $P g m-1$ in Allium fistulosum L. Theor. Appl. Genet. 75, 945-949.

Peffley, E.B., Corgan, J.N., Horak, H.G. and Tanksley, S.D. (1985) Electrophoretic analysis of Allium alien addition lines. Theor. Appl. Genet. 71, 176-184.

Shigyo, M., Tashiro, Y. and Miyazaki. S. (1994) Chromosomal locations of glutamate oxaloacetate transaminase gene loci in Japanese bunching onion (Allium fistulosum L.) and shallot (A. cepa L. Aggregatum group). Jpn. J. Genet. 69, 417-424.

Shigyo, M., Tashiro, Y. Isshiki, S. and Miyazaki, S. (1995a) Chromosomal locations of five isozyme gene loci (Lap-1, Got-1, 6Pgdh-2, Adh-1 and Gdh-1) in shallot (Allium cepa L. Aggregatum group). Jpn. J. Genet. 70, 399-407.

Shigyo, M., Tashiro, Y., Isshiki, S. and Miyazaki, S. (1995b) Chromosomal locations of isocitrate dehydrogenase and phosphoglucoisomerase gene loci in shallot (Allium cepa L. Aggregatum group). Jpn. J. Genet. 70, 627-632.

Soltis, D.E., Haufler, C.H., Darrow, D.C. and Gastony, G.J. (1983) Starch gel electrophoresis of ferns: a compilation of grinding buffers, gel and electrode buffers, and staining schedules. Am. Fern J. 73, 9-27.

Tashiro, Y. (1984) Cytogenetic studies on the origin of Allium 
wakegi Araki. Bull. Fac. Agric. Saga Univ. 56, 1-63.

Tashiro, Y., Miyazaki, S. and Kanazawa, K. (1982) On the shallot cultivated in the countries of southeastern Asia. Bull. Fac. Agric. Saga Univ. 53, 65-73.

Tashiro, Y., Miyazaki, S., Kanazawa, K. and Koshin, S.(1983) Cytogenetic studies in the genus Allium. 6. Production of the reciprocal alien monosomic addition lines between Japanese bunching onion (A. fistulosum L.) and shallot (A. cepa L. Aggregatum group). 1983 Autumn Meet. Jpn. Soc. Hortic.
Sci. Abstract, pp. 146-147.

Ulloa-G, M., Corgan, J.N. and Dunford, M. (1995) Evidence for nuclear-cytoplasmic incompatibility between Allium fistulosum and A. cepa. Theor. Appl. Genet. 90, 746-754.

Van der Meer, Q. P. and Van Benekom, J. L. (1978) Improving the onion crop (Allium cepa L.) by transfer of characters from Allium fistulosum L. Biul. Warzywniczy 22, 87-91.

Wendel, J. F. (1983) Electrophoretic analysis of genetic variation in wild and cultivated Camellia japonica L. Ph. D. Thesis, Univ. North Carolina, Chapel Hill, NC. 